\title{
Numerical Analysis of a Six Stage Forging Process for Producing Hollow Flanged Parts from Tubular Blanks
}

\author{
Grzegorz Winiarski ${ }^{1 *}$, Tomasz Adam Bulzak' ${ }^{1}$ Łukasz Wójcik' ${ }^{1}$ Mirosław Szala' \\ 1 Lublin University of Technology, Nadbystrzycka 36, 20-618, Lublin, Poland \\ * Corresponding author's e-mail: g.winiarski@pollub.pl
}

\begin{abstract}
This paper presents the results of a numerical analysis of a cold forging process for a hollow flanged part. The analysis was performed using Deform 2D/3D. 42CrMo4 steel tubes were used as the billet material, and their material model in the annealed state was described by a constitutive equation. The forming process was performed in six stages with the use of methods such as extrusion with a movable sleeve, open-die extrusion, and upsetting. The objective of the study was to determine whether the proposed forging technique could be used to produce hollow parts with flanges. The determination was made based on the analysis of product geometry quality and process parameters, including the Cockcroft-Latham ductile fracture criterion and forming forces.
\end{abstract}

Keywords: flanging, extrusion, hollow parts, stepped shaft.

\section{INTRODUCTION}

Stepped shafts can be produced with the use of different forming methods. The selection of a production method greatly depends on part geometry, among other things. Parts with complex shapes must be formed in stages using different methods. Pang et al. studied the multistage forging process for a hollow axle shaft [1-3], in which a section of a tubular blank is upset to increase the wall thickness of the tube. The aim of the upsetting operation is to produce the smallest hole possible and reduce the tube section into a rod-like preform. In subsequent operations, the deformed tube section is upset into a flange. Kiliçaslan et al. investigated fracture in the multistage forging process for bolts [4]. Ji et al. studied the fivestage cold extrusion process for shaft parts used in gearboxes [5]. To this end, they combined open-die extrusion and upsetting, these two methods being often employed separately to produce parts. Li et al. investigated the open-die extrusion of a spline shaft [6]. Similar problems were also studied by Wang et al. [7, 8]. In turn, MacCormack et al. employed the upsetting technique to form a spline shape on the head of an aerospace fastener [9]. $\mathrm{Hu}$ et al. used multistage upsetting to form a relatively large diameter flange on the end of a pipe [10]. Quan et al. also studied the multistage upsetting process [11]. They examined the formation of overlap in the electric upsetting of an engine valve. The results demonstrated that such defects primarily result from a sharp decrease in the workpiece temperature. A new twostage extrusion method for producing a flanged part was also presented in [12]. The proposed method is based on the use of a sleeve moving opposite to the direction of the punch to produce a part with a flange of a relatively large diameter and height, when compared to the geometry of the tubular blank. Other methods for producing stepped shafts were studied by Pater et al. [13]. The rolling methods described in their study can be used to produce finished products or semi-finished products for subsequent processing operations. Tomczak in [14] presented a new two-stage forming process for a hollow worm shaft. In the first stage, a hollow stepped shaft is formed from a tube. In the second stage, threads are formed on the largest diameter step of the shaft. 
A review of the literature on the metal forming of stepped or flanged shafts has demonstrated that such products can be produced using various methods. Moreover, as the literature review has shown, the formation of steps or flanges with larger diameters and lengths than those of the billet material requires that the forming process be performed in several stages. The selection of forming methods and their technological parameters depends on the product geometry, material grade and forming temperature. In other words, every product requires a different approach to technology design. Bearing the above in mind, this paper proposes a new process for producing hollow parts with flanges from tubular blanks. Such parts can be used as semi-finished products in the manufacture of sleeves in which mining rotary knives are mounted. The cold forging process was carried out in six stages with the use of extrusion with a movable sleeve, open-die extrusion, and upsetting. The objective of this study was to determine whether the proposed method could be used to form the aforementioned parts. The analysis involved, among other things, examining the changes in product shape and the distributions of key parameters such as the normalized Cockcroft-Latham ductile fracture criterion and forces.

\section{RESEARCH METHOD}

The proposed forging process for producing a hollow flanged part from a tubular blank is schematically shown in Fig 1. This multi-stage forging process is a combination of extrusion with a movable sleeve, open-die extrusion, and upsetting. Schematics of individual stages of the proposed forging process are shown in Fig. 2. In the operation involving extrusion with the movable sleeve (Fig. 2a), a tube section 4a is inserted into a movable sleeve 3 . At the beginning of this operation, a closed die cavity with a height $h_{o 1}$ is located between the sleeve, an ejector 5, and a mandrel 2. As a result of the load exerted by a punch 1 , the cavity is filled. Next, the sleeve is moved opposite to the direction of the punch, which, consequently, increases the height of the flange being extruded. A forging $4 b$ is then deformed by open-die extrusion, as shown in Fig. 2b. During this operation, the outer diameter of the workpiece is reduced. A stepped forging obtained in the open-die extrusion operation is used as the billet material in the second extrusion operation performed with the use of the movable sleeve, as shown in Fig. 2c. This operation is carried out in the same way as that with the tubular blank, the only exception being that, additionally, a bottom die 7 enters the hole of the movable sleeve. In the final stage of the analysed process, a flange is upset in the tapered die cavity, as shown in Fig. 2d.

Technological parameters of individual stages of the forging process are given in Table 1. These parameters were selected on the basis of a numerical analysis that was performed for an axisymmetric mode of deformation using Deform 2D/3D. 42CrMo4 steel was used as the billet material in the analyses. A flow curve of this steel grade in the annealed stated $\left(720^{\circ} \mathrm{C} / 9 \mathrm{~h}\right)$ described by Equation (1) was determined previously with the use of an upsetting test.

$$
\sigma_{p}=1023 \cdot \varphi^{0.2}
$$

The contact conditions between the workpiece and the tools were described by a shear friction model and a friction factor $\mathrm{m}=0.3$. The numerical analysis was carried out under cold forming conditions. The initial temperature of the tools and the tube was set equal to $20^{\circ} \mathrm{C}$. Due to the fact that in the cold working of steel some amount of energy is converted into heat, the transfer of heat between the workpiece and the tools was considered in the analysis. The coefficient of heat transfer between the workpiece and the tools was set equal to $10 \mathrm{~kW} / \mathrm{m}^{2} \mathrm{~K}$. In addition, the velocity of the punch / mandrel / upper die was set to the same value of $100 \mathrm{~mm} / \mathrm{min}$ in every stage of the forging process. The velocity of the movable sleeve, $v_{t}$, was determined based on Equation (2).

$$
v_{t}=v_{s} \cdot \frac{D_{i}^{2}-d_{t i}^{2}}{D_{k i}^{2}-D_{i}^{2}}
$$

where: $v_{s}$ is the velocity of the punch,

$D_{i}$ is the diameter of the hole in the movable sleeve,

$d_{t i}$ is the diameter of the mandrel, $D_{k i}$ is the diameter of the flange.

\section{DISCUSSION OF THE RESULTS}

Table 2 illustrates the change in workpiece geometry in every stage of the analysed forging process. In Stage 1 a tube with an outside diameter of $50 \mathrm{~mm}$ is formed into a hollow part with 


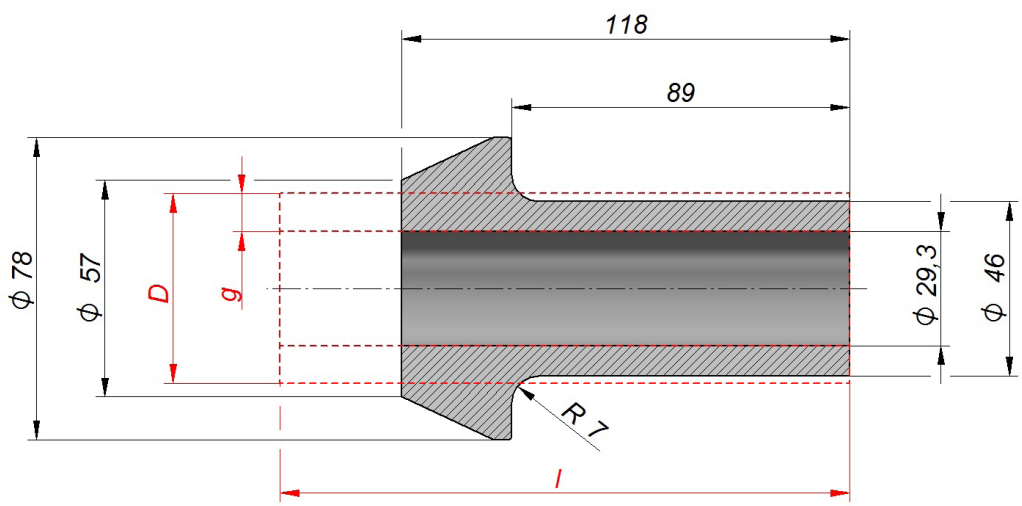

Fig. 1. Schematic of a hollow part with a flange and the outline of a tubular blank

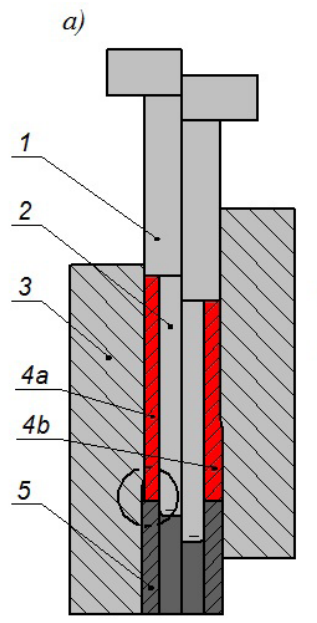

b)

c)

d)
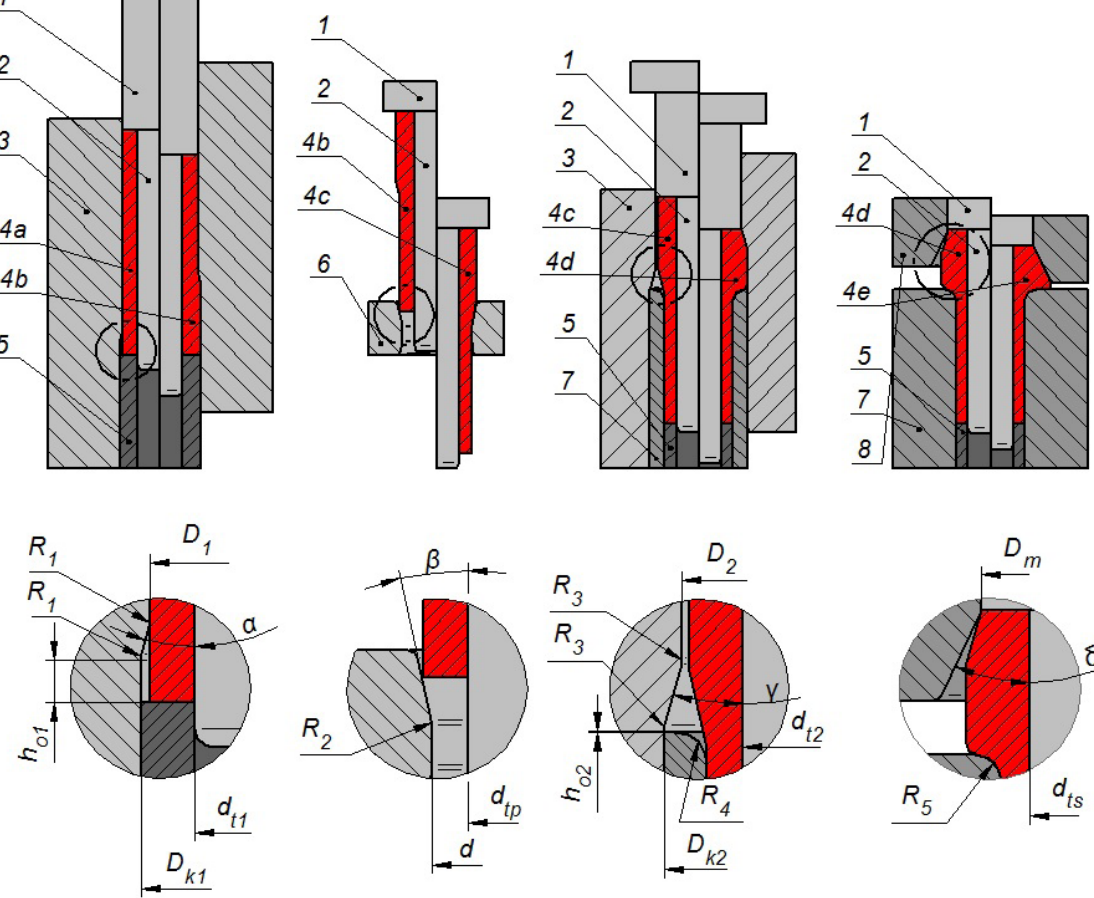

Fig. 2. Schematic design of the forging process for a hollow part with a flange: a) tubular blank is subjected to extrusion with movable sleeve, b) open-die extrusion, c) stepped forging is subjected to extrusion with movable sleeve, d) upsetting; 1- punch, 2- mandrel, 3- moveable sleeve, 4a- billet material, 4b $\div 4 \mathrm{e}-$ workpiece during individual stages of the forging process, 5- ejector, 6- open-die extruding die, 7- bottom die, 8- top die.

Table 1. Technological parameters of individual stages of the forging process for a hollow part with a flange (denoted as in Figs. 1 and 2).

\begin{tabular}{|c|c|c|c|c|c|c|}
\hline Stage No. & $I$ & II & III & IV & $\mathbf{v}$ & VI \\
\hline Process schematic & Fig. 2a & Fig. $2 b$ & Fig. $2 b$ & Fig. 2c & Fig. $2 d$ & Fig. $2 d$ \\
\hline $\begin{array}{l}\text { Technological } \\
\text { parameters }\end{array}$ & $\begin{array}{c}D_{1}=50 \mathrm{~mm} \\
R_{1}=5 \mathrm{~mm} \\
h_{01}=5 \mathrm{~mm} \\
d_{\mathrm{t}_{11}}=29.3 \mathrm{~mm} \\
D_{\mathrm{k} 1}=54 \mathrm{~mm} \\
\alpha=15^{\circ} \\
D=50 \mathrm{~mm} \\
g=10 \mathrm{~mm} \\
\mathrm{l}=150 \mathrm{~mm}\end{array}$ & $\begin{array}{c}\beta=12,5^{\circ} \\
\mathrm{d}=47,9 \mathrm{~mm} \\
\mathrm{~d}_{\mathrm{tp}}=29.3 \mathrm{~mm} \\
\mathrm{R}_{2}=5 \mathrm{~mm}\end{array}$ & $\begin{array}{c}\beta=12,5^{\circ} \\
d=46 \mathrm{~mm} \\
d_{t p}=29.3 \mathrm{~mm} \\
\mathrm{R}_{2}=5 \mathrm{~mm}\end{array}$ & $\begin{array}{c}\mathrm{D}_{2}=57 \mathrm{~mm} \\
\mathrm{R}_{3}=5 \mathrm{~mm} \\
\mathrm{~h}_{\mathrm{o} 2}=0 \mathrm{~mm} \\
\mathrm{R}_{4}=7 \mathrm{~mm} \\
\mathrm{D}_{\mathrm{k} 2}=65 \mathrm{~mm} \\
\mathrm{~V}=15^{\circ} \\
\mathrm{d}_{\mathrm{t} 2}=29,3 \mathrm{~mm}\end{array}$ & $\begin{array}{c}\mathrm{D}_{\mathrm{m}}=57 \mathrm{~mm} \\
\delta=14^{\circ} \\
\mathrm{d}_{\mathrm{ts}}=29,3 \mathrm{~mm} \\
\mathrm{R}_{5}=7 \mathrm{~mm}\end{array}$ & $\begin{array}{c}\mathrm{D}_{\mathrm{m}}=57 \mathrm{~mm} \\
\delta=25^{\circ} \\
\mathrm{d}_{\mathrm{ts}}=29.3 \mathrm{~mm} \\
\mathrm{R}_{5}=7 \mathrm{~mm}\end{array}$ \\
\hline
\end{tabular}


Table 2. Successive stages in the formation of a hollow part with a flange; denoted as in Table 1.

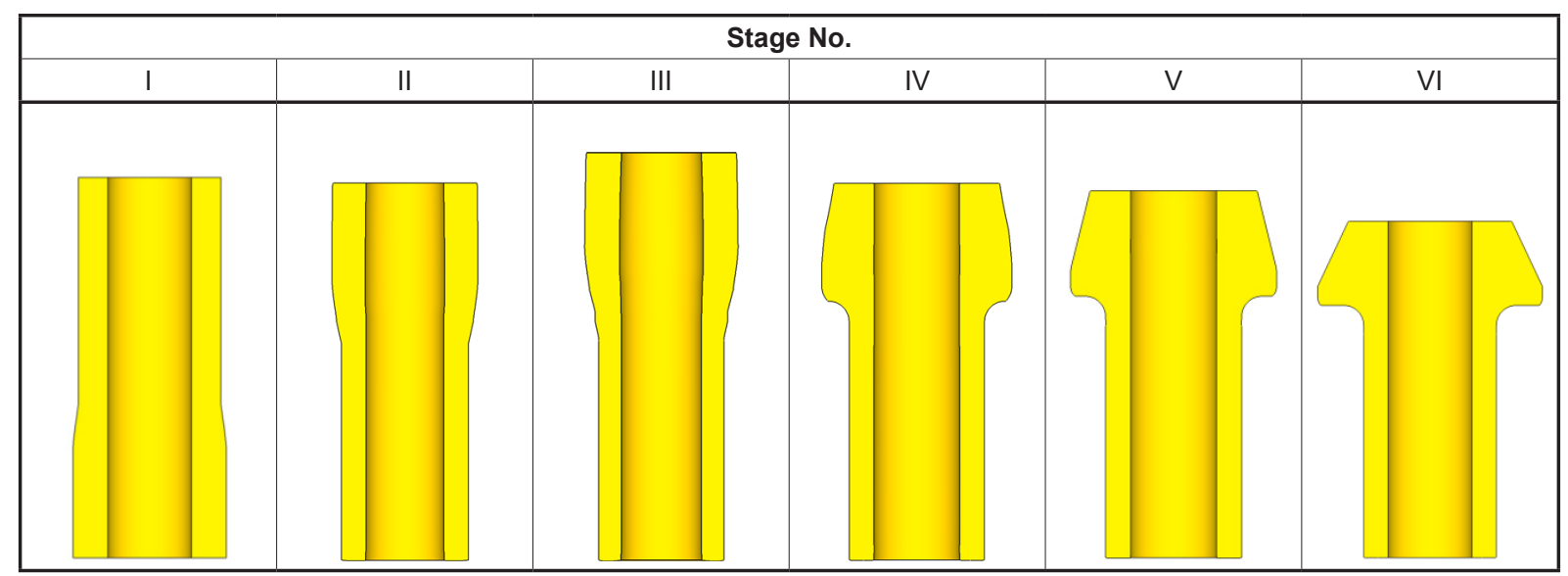

a $54 \mathrm{~mm}$ diameter flange by extrusion with the movable sleeve. This is the maximum obtainable diameter value for the analysed billet material geometry and steel grade, and it was determined in the study described in [15]. Successive stages involve the formation of the workpiece shaft with an outside diameter of $46 \mathrm{~mm}$. In a single-stage open-die extrusion of the workpiece to the required diameter, the material located in front of the extruding die undergoes excessive upsetting, which prevents correct implementation of subsequent forming operations. As a result, the opendie extrusion operation must be performed in two stages; the outside diameter of the tubular section of forging after the first operation is equal to $47.9 \mathrm{~mm}$. The value of the intermediate diameter is selected in such a way to ensure that the crosssectional reduction is the same in both operations. In the analysed case, it is equal to about $12.5 \%$. In spite of thereby selected process parameters, one can still observe slight upsetting of the material the proximity of the tool. This, however, does not have any negative effect on the subsequent operation in which a $65 \mathrm{~mm}$ diameter flange is formed by extrusion with the movable sleeve. The final stage of the analysed forming process is the final forging of a flange that is performed by upsetting in the tapered die cavity. Similarly to the open-die extrusion operation, the upsetting operation is also carried out in two stages for two different angles of the tapered die cavity: $14^{\circ}$ and $25^{\circ}$, respectively. If the upsetting is performed as a single-stage operation (i.e., the $14^{\circ}$ angle is not applied), there occurs local buckling of the workpiece wall, resulting in the formation of overlap. To prevent this defect and thus ensure the correct geometry of the hollow flanged product, the upsetting must be performed in two stages.
For further verification of the proposed forging method, the produced part was also examined for the distributions of strains, stresses, temperatures and the values of the Cockcroft-Latham ductile fracture criterion. It can be observed in Fig. 3a that with an increase in the flange diameter, the effective strains in the flanged region of the part increase from the end face of the flange toward the shank. The maximum effective strains amount to about 2.3 and are located in the flanged region of the workpiece with the biggest diameter. In contrast, the maximum effective strains in the shaft region amount to about 0.7 and are located at the outer surface of the product. The effective stress distribution shown in Fig. 3b demonstrates that, like in the case of the effective strains, the maximum stresses amounting to about $1100 \mathrm{MPa}$ are located in the region of the flange with the biggest diameter. The stress values in the shaft region are close to zero. This is due to the fact that this region of the workpiece is inside the closed die cavity. As a result, the state of stress is similar to triaxial compression. Since the stress components along individual directions have similar values, the effective strain is close to zero. Fig. 3c shows the distribution of values of the normalized Cockcroft-Latham ductile fracture criterion. This criterion is of considerable importance for the analysis of cold forming processes, due to the fact that in such processes the material is strengthened, which may lead to a loss of cohesion of the material. The highest values of this criterion are located on the edge of the flange and amount to about 0.4. In the shaft region of the product, in turn, the maximum values of this criterion amount to about 0.15 and are located at the inner surface of the hole. The obtained values of the normalized Cockcroft-Latham ductile 
fracture criterion can be regarded as safe for the tested $42 \mathrm{CrMo} 4$ steel, because the limit values for this steel grade are in the range of 0.5-0.6. An analysis of the temperature distributions plotted in Fig. 3d demonstrates that the maximum values of about $160^{\circ} \mathrm{C}$ are located in the regions of the highest stresses and strains, i.e., in the region where the flange has the largest diameter. The temperature increase to $160^{\circ} \mathrm{C}$ seems favourable, given the fact that the forming forces decrease with an increase in the temperature of the deformed material. In other regions of the product, the temperature increase is slightly above the initial temperature of $20^{\circ} \mathrm{C}$, due to the low strain value and the large contact area between the material and the tools.

Figure 4 shows the load variation during individual stages of the forging process. In the first operation involving extrusion with the movable sleeve, the punch is under highest load, as shown in Fig. 4a. The maximum load on the punch is about $1700 \mathrm{kN}$, which yields compressive stresses of about $1318 \mathrm{MPa}$ (for a hollow punch of 29.3 and $50 \mathrm{~mm}$ in diameter). It is a safe value due to the fact that the materials for cold forming tools can carry loads of over $2000 \mathrm{MPa}$. In a)

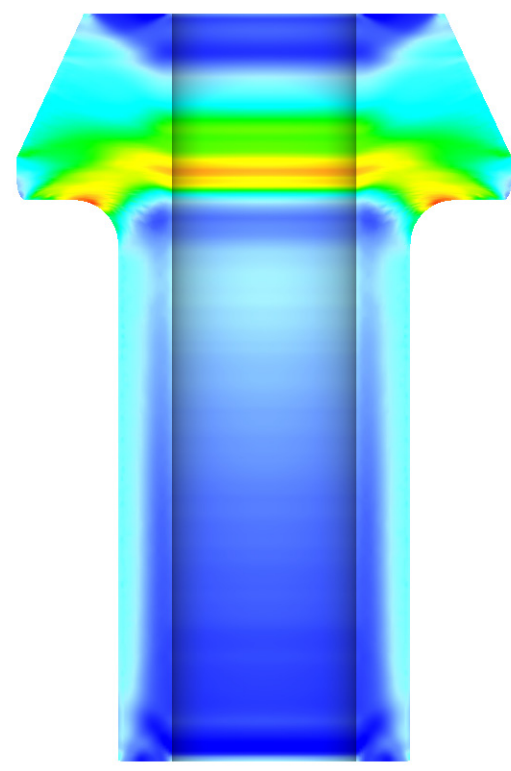

c)

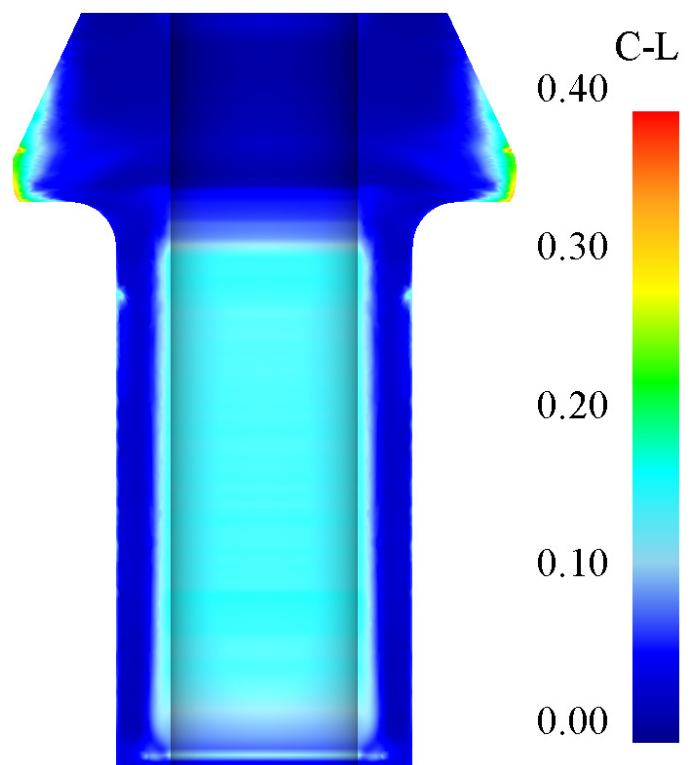

2.30

1.72

1.15

0.57

0.00 b)

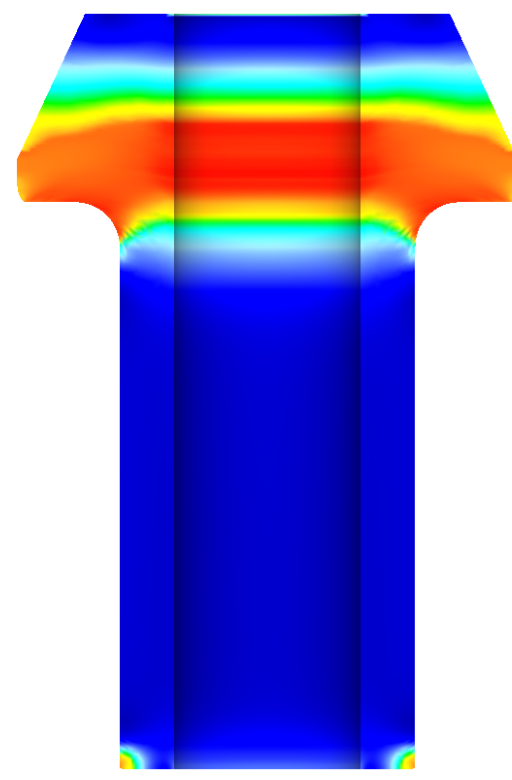

d)

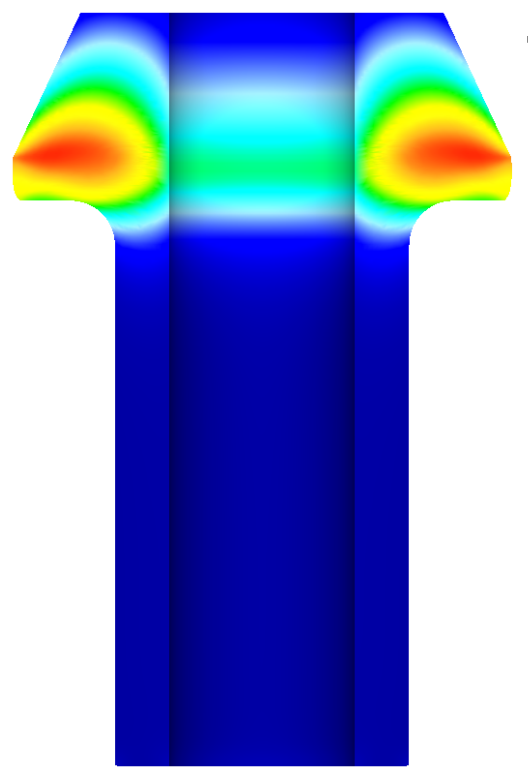

1100.00

Stress

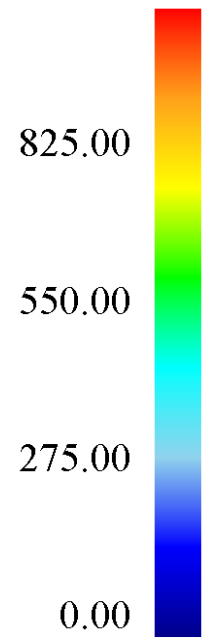

Temperature

160.00

125.00

90.00

55.00

20.00

Fig. 3. Distributions of: a) effective strain, b) effective stress (in MPa), c) the normalized Cockcroft-Latham ductile fracture criterion, and $\mathrm{d}$ ) temperature $\left(\mathrm{in}^{\circ} \mathrm{C}\right)$ in a hollow flanged part. 
the open-die extrusion operation, too, the punch is the most loaded tool and carries the load of about $690 \mathrm{kN}$ and $570 \mathrm{kN}$ in the first and the second stage of open-die extrusion, respectively (Fig. 4b). Since these values are more than two times lower than the loads exerted on the punch during the movable sleeve extrusion operation, the risk of tool overload is very small. In the second operation of extrusion with the movable sleeve, the highest load - as previously- is carried by the punch (Fig. 4c). The maximum load on the punch amounts to $2800 \mathrm{kN}$, which generates compressive stresses reaching a safe value of approximately $1491 \mathrm{MPa}$ (for a hollow punch of 29.3 and $57 \mathrm{~mm}$ in diameter). In the last two stages that involve upsetting in the tapered die cavity, the most loaded tools are the punch and the top die, as shown in Fig. 4d. It is worth mentioning that, in contrast to the punch, the top die can have its strength increased by pre-compression. This means that, again, the punch is the most vulnerable tool. The punch carries the load of $2900 \mathrm{kN}$ and $3700 \mathrm{kN}$ in the first and the second upsetting operation, respectively, which, for a hollow

a)

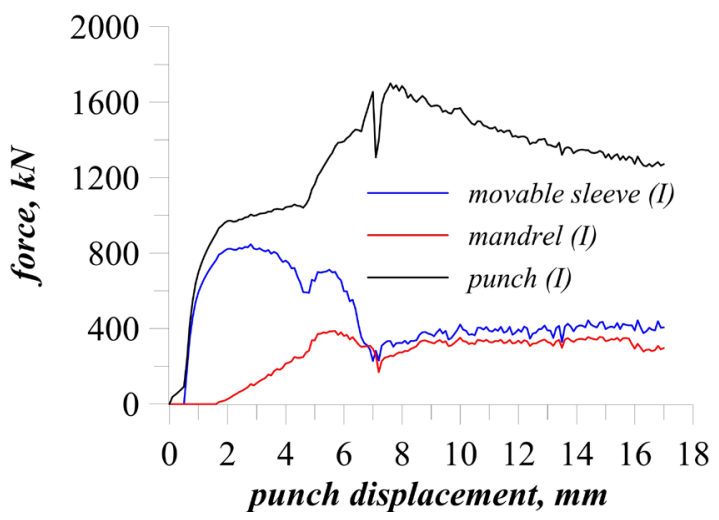

c)

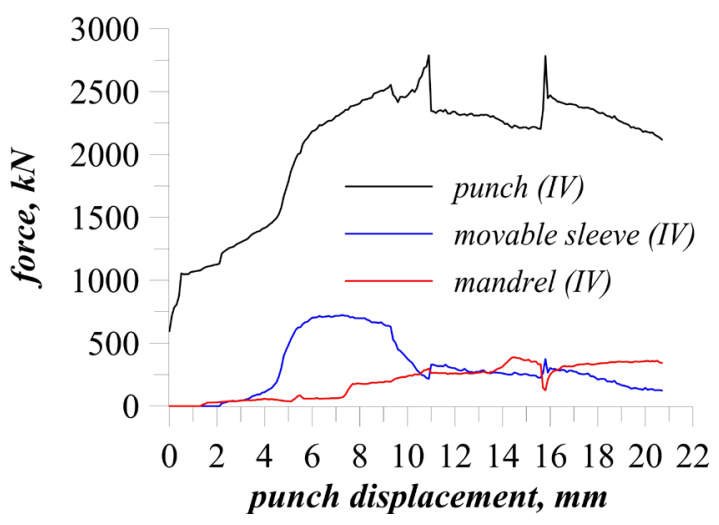

punch of 29.3 and $57 \mathrm{~mm}$ in diameter, yields the compressive stress amounting to a safe value of $1544 \mathrm{MPa}$ and $1970 \mathrm{MPa}$, respectively.

The maximum values of the press load were determined for individual stages of the forging process (Fig. 5). This load is the sum of the maximum loads exerted by the punch, mandrel, and upper die. The highest forming force occurs in the last two stages of the process, when the workpiece undergoes upsetting in the tapered die cavity, and amounts to about $5480 \mathrm{kN}$ and $8750 \mathrm{kN}$, respectively. In the remaining stages the forming forces are much lower. Consequently, the first four stages of the forging process can be performed using a press with a lower force rating (about $3200 \mathrm{kN}$ ), while only the last two stages must be carried out on a press having a force of about $9000 \mathrm{kN}$. Fig. 5 also shows the maximum loads applied to the movable sleeve that must be driven independently of the punch. The highest load of about $850 \mathrm{kN}$ occurs in the first stage of the forging process when a $54 \mathrm{~mm}$ diameter flange is formed.

b)

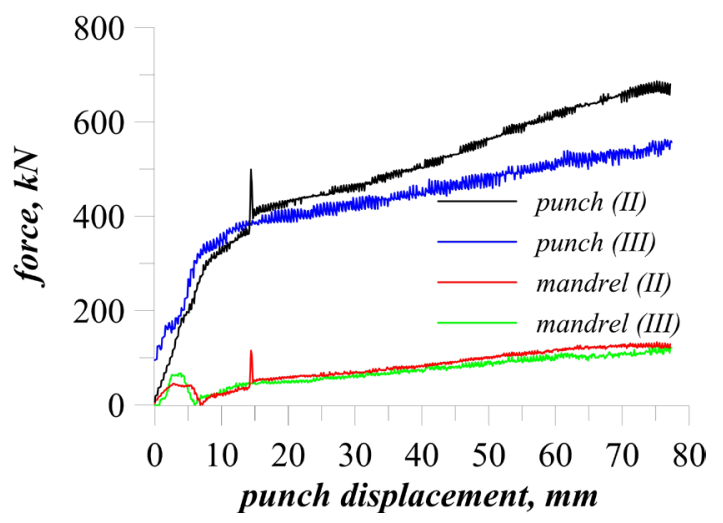

d)

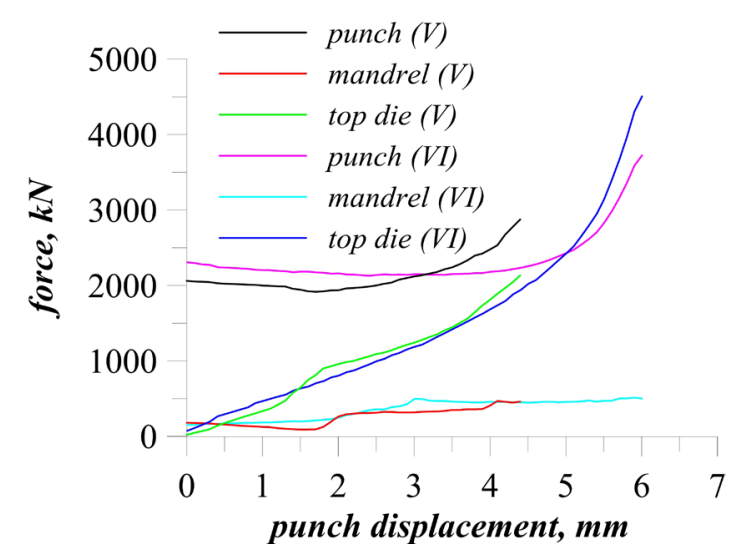

Fig. 4. Load variation in individual stages of the forging process: a) Stage I, b) Stages II and III, c) Stage IV, d) Stages V and VI. 


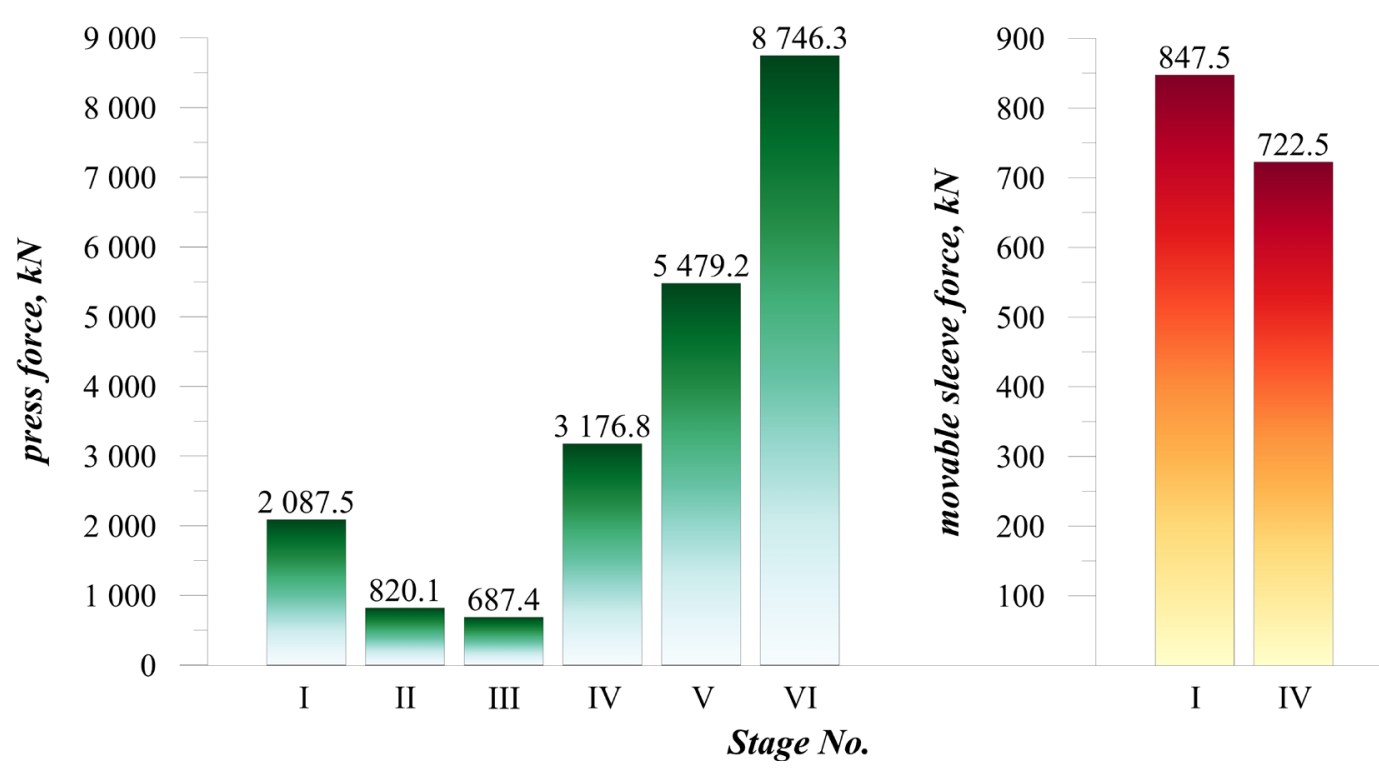

Fig. 5. Press and movable sleeve loads in individual stages of the forging process.

\section{CONCLUSIONS}

The results obtained in the study lead to the following conclusions:

- Extrusion with the movable sleeve is a viable method for forming flanges directly on tubes and stepped preforms; the only failure mode that may occur in the initial stage of the process is local buckling of the workpiece wall, which may result in overlap or underfill;

- In the extrusion operation the moveable sleeve must be driven independently of the punch; the load applied to the sleeve is several times lower than that applied to the punch;

- A significant failure mode that may occur during extrusion with the use of a mandrel is the upsetting of a material in front of the opendie extruding die; in the case under analysis, the maximum permissible sectional reduction that can be made in a single operation is about $12.5 \%$;

- The upsetting of hollow parts in the tapered cavity die may cause local buckling of the workpiece wall, leading to overlap; to prevent this failure mode, the upsetting operation must be performed in stages with gradually increased angles of the tapered die cavity;

- The results confirm that the proposed forging method can be used to form flanges on hollow parts.

\section{Acknowledgement}

The research was financed in the framework of the project: New metal forming technique for producing flanged hollow parts for the mining industry, No. LIDER/1/0003/L-9/17/NCBR/2018. Total cost of the Project: 1197000 PLN. The project is financed by the National Centre for Research and Development under the 9th edition of the LIDER Programme.

\section{REFERENCES}

1. Pang H., Lowrie J. and Ngaile G. Development of a non-isothermal forging process for hollow axle shafts. Procedia Engineering, 207, 2017, 454-459.

2. Pang H. and Ngaile G. Development of a nonisothermal forging process for hollow power transmission shafts. Procedia Manufacturing, 26, 2018, 1509-1516.

3. Pang H. and Ngaile G. Development of a non-isothermal forging process for hollow power transmission shafts. Journal of Manufacturing Processes, 47, 2019, 22-31.

4. Kılıçaslan C. and İnce U. Failure analysis of cold forged $37 \mathrm{Cr} 4$ alloy M10x28 bolts. Engineering Failure Analysis, 70, 2016, 177-187.

5. Ji D., Jin J., Ma W., Xia J., Xia H. and Dong Y. Multistage cold extrusion process and forming rules of shaft parts used in gearbox. Advanced Materials Research, 148-149, 2010, 683-687.

6. Li Y., Zhao S., Fan S. and Yan G. Study on the material characteristic and process parameters of the 
open-die warm extrusion process of spline shaft with 42CrMo steel. Journal of Alloys and Compounds, 571, 2013, 12-20.

7. Wang W., Zhao J. and Zhai R. A forming technology of spur gear by warm extrusion and the defects control. Journal of Manufacturing Processes, 21, 2016, 30-38.

8. Wang W., Zhao J., Zhai R. and Ma R. Variable contour two-step warm extrusion forming of spur gear and the deformation behavior of $20 \mathrm{Cr} 2 \mathrm{Ni} 4 \mathrm{~A}$ steel. The International Journal of Advanced Manufacturing Technology, 88, 2017, 3163-3173.

9. MacCormack C. and Monaghan J. 2D and 3D finite element analysis of a three stage forging sequence. Journal of Materials Processing Technology, 127, 2002, 48-56.

10. Hu X.L. and Wang Z.R. Numerical simulation and experimental study on the multi-step upsetting of a thick and wide flange on the end of a pipe. Journal of Materials Processing Technology, 151, 2004, 321-327.
11. Quan G., Zou Z., Zhang Z. and Pan J. A study on formation process of secondary upsetting defect in electric upsetting and optimization of processing parameters based on multi-field coupling FEM. Materials Research, 19, 2016, 856-864.

12. Winiarski G. and Gontarz A. Numerical and experimental study of producing two-step flanges by extrusion with a movable sleeve. Archives of Metallurgy and Materials, 62, 2017, 495-499.

13. Pater Z., Tomczak J. and Bulzak T. New forming possibilities in cross wedge rolling processes. Archives of Civil and Mechanical Engineering, 18, 2018, 149-161.

14. Tomczak J. Studium procesów obciskania obrotowego odkuwek drążonych. Politechnika Lubelska, 2016.

15. Winiarski G., Bulzak T., Wójcik Ł. and Szala M. Effect of tool kinematics on tube flanging by extrusion with a moving sleeve. Advances in Science and Technology Research Journal, 13, 2019, 210-216. 